\title{
Lung function impairment, COPD hospitalisations and subsequent mortality
}

\author{
Judith Garcia-Aymerich, ${ }^{1,2,3,4}$ Ignasi Serra Pons, ${ }^{1,2}$ David M Mannino, 5,6 \\ Andrea K Maas, ${ }^{7}$ David P Miller, ${ }^{8}$ Kourtney J Davis ${ }^{8}$
}

${ }^{1}$ Centre for Research in

Environmental Epidemiology (CREAL), Barcelona, Spain

${ }^{2}$ Municipal Institute of Medical Research (IMIM-Hospital del

Mar), Barcelona, Spain

${ }^{3}$ CIBER Epidemiologia y Salud

Pública (CIBERESP), Barcelona,

Spain

${ }^{4}$ Department of Experimental and Health Sciences, Universitat Pompeu Fabra, Barcelona, Spain ${ }^{5}$ Department of Preventive Medicine and Environmental Health, University of Kentucky Medical Center, Lexington, Kentucky, USA

${ }^{6}$ Division of Pulmonary and Critical Care Medicine, University of Kentucky Medical Center, Lexington, Kentucky, USA

${ }^{7}$ Division of Pulmonary and Critical Care Medicine, University of South Carolina, Columbia, South Carolina, USA

${ }^{8}$ Worldwide Epidemiology, GlaxoSmithKline, Research Triangle Park, North Carolina, USA

\section{Correspondence to}

David M Mannino, Division of Pulmonary and Critical Care

Medicine, University of Kentucky Medical Center, 800 Rose Street, MN 614, Lexington, KY 40536, USA; dmannino@uky.edu

Received 5 October 2010 Accepted 23 December 2010 Published Online First 22 April 2011

\section{ABSTRACT \\ Background Hospitalisations and their sequelae} comprise key morbidities in the natural history of chronic obstructive pulmonary disease (COPD). A study was undertaken to examine the associations between lung function impairment and COPD hospitalisation, and COPD hospitalisation and mortality.

Methods The analysis included a population-based sample of 20571 participants with complete demographic, lung function, smoking, hospitalisation and mortality data, with 10-year median follow-up. Participants were classified by prebronchodilator lung function according to the modified Global Initiative on Obstructive Lung Disease (GOLD) criteria.

Hospitalisations were defined by the presence of a COPD discharge diagnosis (ICD-9 codes 490-496). Incidence rate ratios (IRR) of COPD admissions and hazard ratios (HR) of mortality with respective $95 \% \mathrm{Cl}$ were calculated, adjusted for potential confounders.

Results The prevalence of modified GOLD categories was normal (36\%), restricted (15\%), GOLD stage 0 (22\%), GOLD stage 1 (13\%), GOLD stage $2(11 \%)$ and GOLD stages 3 or 4 (3\%). Adjusted IRRs (and 95\% CI) indicated an increased risk of COPD hospitalisation associated with each COPD stage relative to normal lung function: 4.7 (3.7 to 6.1), 2.1 (1.6 to 2.6), 3.2 (2.6 to 4.0), 8.0 (6.4 to 10.0) and 25.5 (19.5 to 33.4) for the restricted, GOLD stage 0, GOLD stage 1 , GOLD stage 2 and GOLD stages 3 or 4, respectively. Hospitalisation for COPD increased the risk of subsequent mortality (HR 2.7, $95 \% \mathrm{Cl} 2.5$ to 3.0), controlling for severity, number of prior hospitalisations and other potential confounders. The increase in mortality associated with admission was very similar across the modified GOLD stages.

Conclusions COPD severity was associated with a higher rate of severe exacerbations requiring hospitalisation, although severe exacerbations at any stage were associated with a higher risk of short-term and long-term all-cause mortality.

Chronic obstructive pulmonary disease (COPD) is responsible for a significant medical and economic burden in the USA and is expected to be the third leading cause of worldwide mortality by the year $2020 .^{1}$ In 2000 in the USA 726000 people were hospitalised for an exacerbation of COPD, with people aged $>65$ years responsible for more than one-half of these. ${ }^{2}$ Almost 120000 people in the USA died with COPD as the underlying cause of death in $2000 .^{2}$ However, this number may actually be higher because many decedents with COPD have their deaths attributed to other causes, ${ }^{3}$ and serious comorbid conditions are common in this population. $^{4-6}$
Acute exacerbations of COPD frequently result in hospital admission and account for a large proportion of the clinical, economical and social impact of this disease, including an increased risk of mortality. Impaired lung function has been identified as a risk factor of hospital admission due to a COPD exacerbation in several studies including different settings, designs and methods, and independent of respiratory symptoms, quality of life or blood gas exchange..$^{7-12}$ Unfortunately, the limited sample size and/or the narrow variability in lung function has not allowed previous studies to quantify the increase in the risk of COPD admissions associated with a range of impaired lung function levels.

Previous studies of hospitalisations and outcomes have focused on in-hospital mortality, ${ }^{6}{ }^{13}$ rehospitalisations and/or resource utilisation ${ }^{14-16}$ or mortality at short periods of time ( $\leq 2$ years). ${ }^{16-19}$ In these studies the demographic data were limited, ${ }^{20}$ the range of lung function impairment was narrow and cohorts consisted of relatively small numbers of only previously-diagnosed patients with COPD. Additionally, the influence of COPD admissions and COPD severity stage on mortality risk has never been quantitatively assessed.

The goal of this study was to examine the associations between (1) lung function impairment and COPD hospitalisation, and (2) COPD hospitalisation and mortality in two large diverse population-based cohorts. This design allows us to determine the characteristics of the population admitted to hospital for severe COPD events and to profile the short- and long-term outcomes related to these events. Such information can identify higher risk subgroups for whom targeted interventions and monitoring may be warranted.

\section{METHODS \\ Study population}

For this analysis we combined data from the Cardiovascular Health Study (CHS) and Atherosclerosis Risk in Communities (ARIC) cohorts, both of which were population-based NIH cohorts initiated in the late 1980s to study risk factors for the development and progression of heart disease and stroke. These cohorts included subjects of different ages ( $\geq 65$ years for CHS and $45-64$ years for ARIC) and had comprehensive evaluations including lung function and longitudinal follow-up. Combining these two cohorts into one larger study population provides data over a wider age range, better reflecting the US adult population.

The CHS cohort consisted of 5201 subjects selected using Medicare eligibility lists provided 
by the US Healthcare Financing Administration for four communities: Forsyth County, North Carolina; Pittsburgh, Pennsylvania; Sacramento County, California; and Washington County, Maryland from May 1989 to May 1990. Subjects completed a questionnaire (including information on respiratory symptoms and diagnoses, medical history and smoking status), clinical examination and underwent spirometric testing at baseline and 4 years. They were followed through to the end of 1999. Details of the CHS are published elsewhere. ${ }^{21}$

The ARIC study was initiated in 1987 as a longitudinal population-based study of the aetiology and clinical sequelae of atherosclerosis in 15792 adults. Study protocols were approved for protection of human subjects. Participants were selected from the entire population by probability sampling from four US communities: Forsyth County, NC; Minneapolis, MN; Washington County, MD; and Jackson, MS (where only African Americans were sampled), and followed through 1998. Specific details of the ARIC study are published elsewhere. ${ }^{22}$

Our analysis was limited to CHS or ARIC participants who provided baseline information on respiratory symptoms and diagnoses, medical history and who underwent adequate pulmonary function testing at the baseline examination. There were no differences in age or gender between subjects included and those excluded because of missing data ( $n=216$ in CHS, $\mathrm{n}=206$ in ARIC).

\section{Variables and instruments}

In both studies, spirometry was conducted using a volumedisplacement water-sealed spirometer. At least three acceptable spirograms were obtained from a minimum of five forced expirations. The best single spirogram was identified by computer and confirmed by a technician. Quality assurance was provided by the CHS Pulmonary Function Center for CHS and the ARIC investigators for ARIC, and the procedures followed contemporary American Thoracic Society guidelines. ${ }^{23}$ Several measures of lung function were used in this analysis: forced expiratory volume in $1 \mathrm{~s}\left(\mathrm{FEV}_{1}\right)$, forced vital capacity (FVC) and the $\mathrm{FEV}_{1} /$ FVC ratio. We used the prediction equations derived from the Third National Health and Nutrition Examination Survey to define the predicted values of $\mathrm{FEV}_{1}$ and FVC. ${ }^{24}$ We defined a subject as having a respiratory symptom if they reported cough, phlegm, dyspnoea or wheeze.

A modification of the GOLD criteria was used to classify subjects according to their stage of COPD ${ }^{25} 26$ : GOLD stages 3 or $4\left(\mathrm{FEV}_{1} / \mathrm{FVC}<0.70\right.$ and $\mathrm{FEV}_{1}<50 \%$ predicted $)$, GOLD stage 2 $\left(\mathrm{FEV}_{1} / \mathrm{FVC}<0.70\right.$ and $\mathrm{FEV}_{1} \geq 50$ to $<80 \%$ predicted), GOLD stage $1\left(\mathrm{FEV}_{1} / \mathrm{FVC}<0.70\right.$ and $\mathrm{FEV}_{1} \geq 80 \%$ predicted), restricted $\left(\mathrm{FEV}_{1} / \mathrm{FVC} \geq 70 \%\right.$ and $\mathrm{FVC}<80 \%$ predicted), GOLD stage 0 (presence of respiratory symptoms in the absence of any lung function abnormality) and no lung disease (table 1). Bronchodilator response was not evaluated so classification is based on the 'prebronchodilator' level. Only the baseline pulmonary function data were used to stratify participants, and they remained in these groups for interpretation of prevalent risk and incident or recurrent events.

Age, sex, race (white or black) and highest education level $(<12$ years, 12 years or $>12$ years) obtained were self-reported. Respondents with positive responses to the questions 'Have you ever smoked cigarettes?' and 'Do you now smoke cigarettes?' were classified as never, former or current smokers, respectively. A modification of the Baecke questionnaire was used to assess physical activity. ${ }^{27} 28$ We added the three components (work, leisure and sports indices) and divided the subjects into four quartiles of least to most active. Body mass index (BMI) was
Table 1 Characteristics of the study population from the

Atherosclerosis Risk in Communities Study (ARIC) 1986-9 and

Cardiovascular Health Study (CHS) 1989-90, with median follow-up of 10 person-years

\begin{tabular}{|c|c|c|c|c|}
\hline & Total $\mathbf{n}(\%)$ & $\begin{array}{l}\geq 1 \text { COPD } \\
\text { admission n (\%) }\end{array}$ & $\begin{array}{l}\text { Person-years } \\
\text { of follow-up }\end{array}$ & $\begin{array}{l}\text { Death rate } \\
\text { per } 1000 \\
\text { person-years }\end{array}$ \\
\hline Total & 20571 & 1537 (7) & 199165 & 15.4 \\
\hline \multicolumn{5}{|l|}{ Age group } \\
\hline $45-49$ & $4169(20)$ & $48(3)$ & 42297 & 3.9 \\
\hline $50-54$ & $4047(20)$ & $96(6)$ & 40835 & 6.4 \\
\hline $55-59$ & 3806 (19) & $171(11)$ & 37666 & 10.8 \\
\hline $60-64$ & $3564(17)$ & $283(18)$ & 34059 & 17.9 \\
\hline $65-71$ & $2130(10)$ & $345(23)$ & 20419 & 20.3 \\
\hline $72-75$ & $1175(6)$ & $241(16)$ & 10798 & 31.2 \\
\hline $76-79$ & $1172(6)$ & $255(17)$ & 9731 & 51.9 \\
\hline 80 and older & $508(2)$ & $98(6)$ & 3359 & 109.5 \\
\hline \multicolumn{5}{|l|}{ Gender } \\
\hline Female & $11420(56)$ & $678(44)$ & 112458 & 11.9 \\
\hline Male & $9151(44)$ & $859(56)$ & 86707 & 19.9 \\
\hline \multicolumn{5}{|l|}{ Education (years) } \\
\hline$<12$ & $5074(25)$ & $597(39)$ & 47124 & 24.4 \\
\hline 12 & $6439(31)$ & $446(29)$ & 63080 & 12.4 \\
\hline$>12$ & $9021(44)$ & $490(32)$ & 88586 & 12.7 \\
\hline \multicolumn{5}{|l|}{ Race } \\
\hline White & $16170(79)$ & 1395 (91) & 156976 & 15.4 \\
\hline Black & $4401(21)$ & $142(9)$ & 42188 & 15.3 \\
\hline \multicolumn{5}{|l|}{ Smoking status } \\
\hline Never & $8409(41)$ & $296(19)$ & 82628 & 12.1 \\
\hline Former & 7119 (35) & $622(40)$ & 68448 & 17.0 \\
\hline Current & $5025(24)$ & $618(40)$ & 47913 & 18.6 \\
\hline \multicolumn{5}{|l|}{ Physical activity } \\
\hline Low & $6075(30)$ & $684(45)$ & 56411 & 23.9 \\
\hline Intermediate-low & $5358(26)$ & $407(27)$ & 51831 & 15.5 \\
\hline Intermediate-high & $5030(24)$ & $275(18)$ & 49660 & 11.8 \\
\hline High & $4104(20)$ & $170(11)$ & 41238 & 7.9 \\
\hline \multicolumn{5}{|c|}{ Body mass index $\left(\mathrm{kg} / \mathrm{m}^{2}\right)$} \\
\hline$<20$ & $819(4)$ & $124(8)$ & 7453 & 29.0 \\
\hline $20-24$ & $6344(31)$ & $499(33)$ & 61324 & 15.3 \\
\hline $25-29$ & $8207(40)$ & $570(37)$ & 79710 & 15.2 \\
\hline$\geq 30$ & $5184(25)$ & $342(22)$ & 50508 & 13.9 \\
\hline \multicolumn{5}{|l|}{ Modified GOLD stage ${ }^{*}$} \\
\hline Normal & $7329(36)$ & $132(9)$ & 74025 & 8.3 \\
\hline Restricted & 3169 (15) & $202(13)$ & 30646 & 15.9 \\
\hline GOLD 0 & $4454(22)$ & $191(12)$ & 43604 & 13.4 \\
\hline GOLD 1 & $2696(13)$ & $287(19)$ & 25072 & 23.3 \\
\hline GOLD 2 & $2264(11)$ & $444(29)$ & 20955 & 25.3 \\
\hline GOLD 3 or 4 & $596(3)$ & $281(18)$ & 4863 & 55.3 \\
\hline \multicolumn{5}{|l|}{ Respiratory symptoms } \\
\hline No & $11121(54)$ & $412(27)$ & 109688 & 11.4 \\
\hline Yes & $9450(46)$ & $1125(73)$ & 89477 & 20.4 \\
\hline \multicolumn{5}{|l|}{ Diabetes } \\
\hline No & $17850(87)$ & $1267(83)$ & 174932 & 13.1 \\
\hline Yes & $2588(13)$ & 267 (17) & 22935 & 32.9 \\
\hline \multicolumn{5}{|l|}{ Heart disease } \\
\hline No & 17435 (85) & $1042(68)$ & 171332 & 12.4 \\
\hline Yes & 3136 (15) & $495(32)$ & 27832 & 33.6 \\
\hline \multicolumn{5}{|l|}{ Source study } \\
\hline ARIC & $15586(76)$ & $598(39)$ & 154857 & 9.3 \\
\hline CHS & $4985(24)$ & $939(61)$ & 44308 & 36.7 \\
\hline
\end{tabular}

*Modified Global Initiative on Obstructive Lung Disease (GOLD): normal (no lung disease), restricted ( $\mathrm{FEV}_{1} / \mathrm{FVC} \geq 0.70$ and $\mathrm{FVC}<80 \%$ predicted), GOLD stage 0 (presence of respiratory symptoms in the absence of any lung function abnormality), GOLD Stage 1 (FEV $/$ FVC $<0.70$ and $\mathrm{FEV}_{1} \geq 80 \%$ ), GOLD stage $2\left(\mathrm{FEV}_{1} / \mathrm{FVC}<0.70\right.$ and $\mathrm{FEV}_{1} \geq 50 \%$ to $<80 \%$ predicted) and GOLD stages 3 or $4\left(\mathrm{FEV}_{1} / \mathrm{FVC}<0.70\right.$ and $\mathrm{FEV}_{1}<50 \%$ predicted). 
calculated as weight divided by height squared $\left(\mathrm{kg} / \mathrm{m}^{2}\right) \cdot{ }^{29}$ Subjects were classified as having diabetes if they either reported a diagnosis of diabetes at baseline or had elevated fasting or postglucose load glucose levels at the baseline examination. Subjects reporting a diagnosis of a previous myocardial infarction, stroke, heart failure, angina or transient ischaemic attacks were classified as having cardiovascular disease at the baseline examination.

\section{Outcomes}

Hospitalisation discharge data were searched and COPD events were defined as any hospitalisations occurring during follow-up that included a COPD or related condition (ICD-9 code 490-496) discharge code. Mortality data were obtained from death certificates. Only all-cause mortality was considered.

\section{Statistical analysis}

Data from the ARIC and CHS cohorts were pooled. A variable indicating study source (ARIC or CHS) was included as a potential confounder or effect modifier in all the analyses that follow. Characteristics of the study population were described as number and percentage. For each subject group, total personyears of follow-up and death rate (number of deaths/1000 person years) were calculated.

Kaplan-Meier curves of time to first COPD admission were plotted according to the modified GOLD stage and the stages were compared using the log rank test. The crude and adjusted associations between modified GOLD stage and COPD hospitalisation rate were assessed using zero-inflated negative binomial regression, and goodness of fit was tested. The following variables were tested as potential confounders: age (as a continuous), gender, education, race, smoking, physical activity, BMI (in four categories), diabetes and heart disease. Variables were included in the final model if they were independently related to the outcome or the exposure, or modified estimates for the remaining variables by at least $15 \%$. Respiratory symptoms were not considered as potential confounders due to their overlap with the GOLD stage 0 definition.

Kaplan-Meier curves of time to death were plotted according to incident COPD hospitalisation status and compared using the log rank test. The crude and adjusted association between COPD hospitalisation and mortality were analysed by means of parametric tests using exponential distribution, adjusting for confounders, and including previous COPD hospitalisations as a time-varying exposure. The final model was further stratified according to modified GOLD stage.

All analyses were conducted with SAS Version 9.1 (SAS Institute), SUDAAN version 9.0 (RTI, Research Triangle Park, NC) and STATA release 10.0 (StataCorp LP, 2008).

\section{RESULTS}

A total of 20571 subjects (15586 from ARIC and 4985 from CHS) were included: $56 \%$ women, mean age 59 years, with $35 \%$ former and $24 \%$ current smokers. The prevalence of modified GOLD categories was: normal (36\%), restricted $(15 \%)$, GOLD stage $0(22 \%)$, GOLD stage $1(13 \%)$, GOLD stage $2(11 \%)$ and GOLD stages 3 or 4 (3\%). The proportion of former and current smokers was higher in GOLD stages 1-4, while never smokers were more predominant in normal, restricted or GOLD stage 0 subjects. Clinical and demographic data describing the analysis cohort, including exacerbation and mortality rates, are shown in table 1.

A total of 1537 subjects (7\%) had at least one COPD admission during follow-up. Among those hospitalised, the median rate of admission was 0.20/year (p25-p75: 0.10-0.44). Figure 1

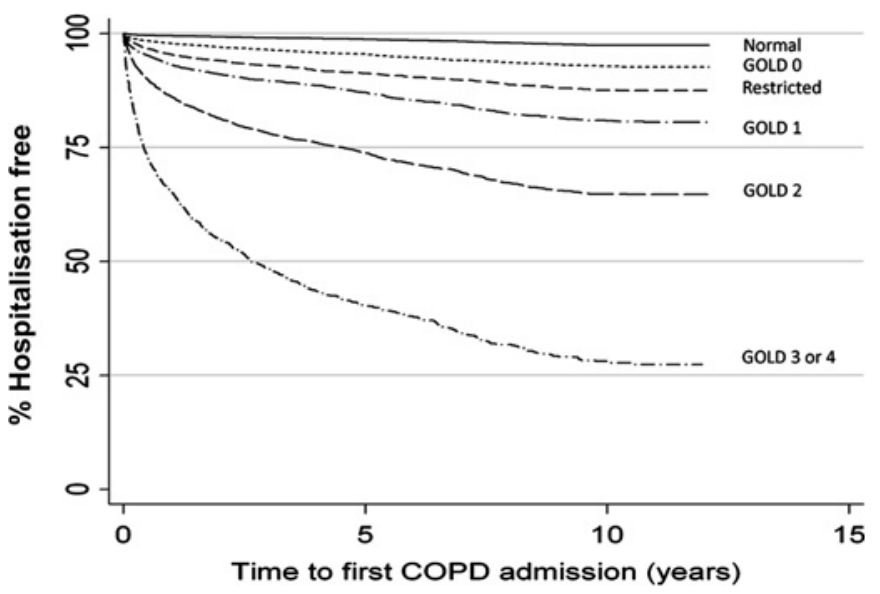

Figure 1 Time to first hospitalisation for chronic obstructive pulmonary disease (COPD) by modified Global Initiative on Obstructive Lung Disease (GOLD) stage. Modified GOLD stages: normal (no lung disease), restricted $\left(\mathrm{FEV}_{1} / \mathrm{FVC} \geq 0.70\right.$ and $\mathrm{FVC}<80 \%$ predicted), GOLD stage 0 (presence of respiratory symptoms in the absence of any lung function abnormality), GOLD stage 1 (FEV $/$ FVC $<0.70$ and $\mathrm{FEV}_{1} \geq 80 \%$ ), GOLD stage $2\left(\mathrm{FEV}_{1} / \mathrm{FVC}<0.70\right.$ and $\mathrm{FEV}_{1} \geq 50 \%$ to $<80 \%$ predicted) and GOLD stages 3 or 4 (FEV $/$ FVC $<0.70$ and $\mathrm{FEV}_{1}<50 \%$ predicted).

shows that each of the GOLD stages, including GOLD 0 and restricted, had an increased risk of COPD admission compared with the normal group ( $\mathrm{p}<0.001$, log-rank test). After adjusting for potential confounders, the risk of an incident COPD hospitalisation (IRR and 95\% CI) by COPD stage was 4.7 (3.7 to 6.1), 2.1 (1.6 to 2.6), 3.2 (2.6 to 4.0), 8.0 (6.4 to 10.0) and 25.5 (19.5 to 33.4) for the restricted, GOLD stage 0 , GOLD stage 1 , GOLD stage 2 and GOLD stages 3 or 4 categories, respectively (table 2).

Figure 2 shows the risk of death in study subjects with and without a COPD-related admission. Having had a COPD admission increased the risk of all-cause mortality in the study sample (HR 14.3 (95\% CI 13.0 to 15.7), p<0.001). This association was reduced but still remained statistically significant after adjusting for modified GOLD stages, previous COPD admissions (as a time-varying variable) and other confounders (table 3). The magnitude of the association between having a COPD admission and mortality was higher than the estimates for any of the modified GOLD stages except for GOLD stages 3 or 4 (table 3). Figure 3 shows that the increase in mortality associated with admission was very similar across the modified GOLD stages. All

Table 2 Crude and adjusted* risk (incidence rate ratio, IRR) of incident hospitalisations for chronic obstructive pulmonary disease

\begin{tabular}{lll}
\hline & Crude IRR (95\% CI) & Adjusted ${ }^{*}$ IRR (95\% Cl) \\
\hline $\begin{array}{ll}\text { Modified GOLD stage } \\
\quad \text { Normal }\end{array}$ & 1.0 & 1.0 \\
Restricted & $4.3(3.3$ to 5.5$)$ & $4.7(3.7$ to 6.1$)$ \\
GOLD 0 & $2.3(1.8$ to 2.9$)$ & $2.1(1.6$ to 2.6$)$ \\
GOLD 1 & $3.9(3.1$ to 4.9$)$ & $3.2(2.6$ to 4.0$)$ \\
GOLD 2 & $8.6(6.9$ to 10.7$)$ & $8.0(6.4$ to 10.0$)$ \\
GOLD 3 or 4 & $22.5(17.3$ to 29.4$)$ & $25.5(19.5$ to 33.4$)$ \\
\hline
\end{tabular}

*Zero-inflated negative binomial regression adjusted for age, gender, education, smoking, physical activity, diabetes, heart disease and cohort (Atherosclerosis Risk in Communities Study/Cardiovascular Health Study).

†Modified Global Initiative on Obstructive Lung Disease (GOLD): normal (no lung disease), restricted $\left(\mathrm{FEV}_{1} / \mathrm{FVC} \geq 0.70\right.$ and $\mathrm{FVC}<80 \%$ predicted), GOLD stage 0 (presence of respiratory symptoms in the absence of any lung function abnormality), GOLD stage 1 $\left(\mathrm{FEV}_{1} / \mathrm{FVC}<0.70\right.$ and $\mathrm{FEV}_{1} \geq 80 \%$ ), GOLD stage $2\left(\mathrm{FEV}_{1} / \mathrm{FVC}<0.70\right.$ and $\mathrm{FEV}_{1} \geq 50 \%$ to $<80 \%$ predicted) and GOLD stages 3 or 4 ( $\mathrm{FEV}_{1} / \mathrm{FVC}<0.70$ and $\mathrm{FEV}_{1}<50 \%$ predicted). 


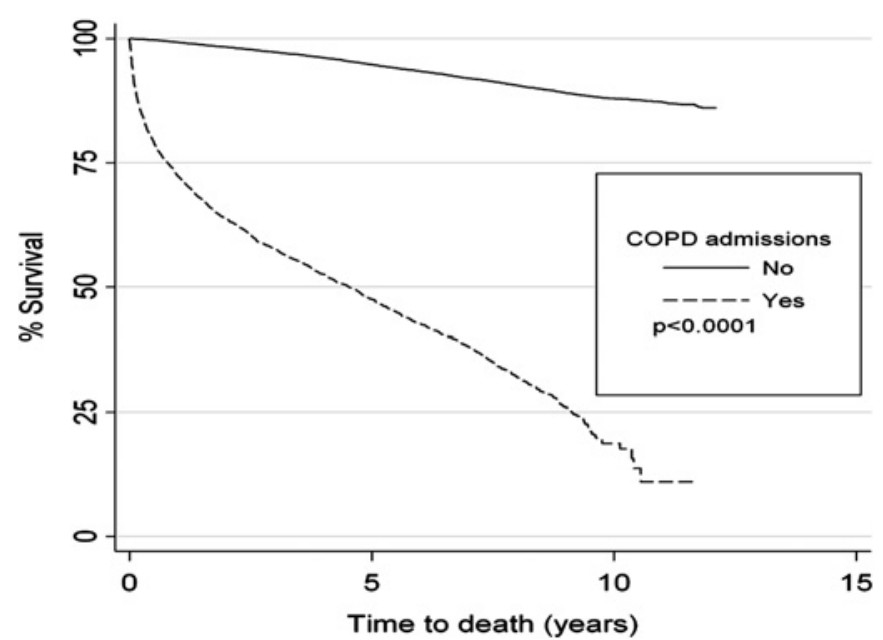

Figure 2 Time to death by having had at least one previous admission for chronic obstructive pulmonary disease (COPD).

results were unchanged after stratifying according to study source (ARIC or CHS).

\section{DISCUSSION}

This analysis of large population-based cohorts had two key findings. The first was that the degree of lung function impairment at baseline was independently associated with the risk of subsequent COPD-related hospitalisations (figure 1, table 2). Of note, this finding was also observed in subjects who did not meet the traditional criteria for COPD - that is, those who had respiratory symptoms at baseline in the absence of lung function impairment (GOLD stage 0) and those who had a normal $\mathrm{FEV}_{1}$ / FVC but an $\mathrm{FEV}_{1}$ or FVC $<80 \%$ of their predicted value (restricted spirometry). The second and more novel finding was that a COPD-related hospitalisation at any level of baseline lung function impairment predicted subsequent mortality that was similar across the differing levels of lung function impairment (figure 3).

This population-based study offers unique information compared with others in the published literature by not requiring the presence of COPD or other lung function impairment for study entry. ${ }^{15} 30$ Thus, COPD-related hospitalisations

Table 3 Adjusted risk (HR) of all-cause mortality associated with incident hospitalisation for chronic obstructive pulmonary disease (COPD), controlling for COPD disease severity

\begin{tabular}{ll}
\hline & Adjusted $^{*}$ HR $\mathbf{( 9 5 \% ~ C l )}$ \\
\hline $\begin{array}{l}\text { COPD admission } \\
\text { Modified GOLD staget }\end{array}$ & $2.7(2.5$ to 3.0$)$ \\
$\quad$ Normal & 1.0 \\
Restricted & $1.8(1.5$ to 2.1$)$ \\
GOLD 0 & $1.2(1.1$ to 1.4$)$ \\
GOLD 1 & $1.4(1.2$ to 1.6$)$ \\
GOLD 2 & $1.5(1.3$ to 1.8$)$ \\
GOLD $3 / 4$ & $2.7(2.2$ to 3.4$)$
\end{tabular}

*Parametric survival regression model also adjusted for previous COPD admissions (during the study period), age, gender, education, race, smoking, physical activity, body mass index, diabetes, heart disease and cohort (Atherosclerosis Risk in Communities Study/ Cardiovascular Health Study).

†Modified Global Initiative on Obstructive Lung Disease (GOLD): normal (no lung disease), restricted ( $\mathrm{FEV}_{1} / \mathrm{FVC} \geq 0.70$ and $\mathrm{FVC}<80 \%$ predicted), GOLD stage 0 (presence of respiratory symptoms in the absence of any lung function abnormality), GOLD stage 1

( $\mathrm{FEV}_{1} / \mathrm{FVC}<0.70$ and $\mathrm{FEV}_{1} \geq 80 \%$ ), GOLD stage $2\left(\mathrm{FEV}_{1} / \mathrm{FVC}<0.70\right.$ and $\mathrm{FEV}_{1} \geq 50 \%$ to $<80 \%$ predicted) and GOLD stages 3 or 4 ( $\mathrm{FEV}_{1} / \mathrm{FVC}<0.70$ and $\mathrm{FEV}_{1}<50 \%$ predicted).

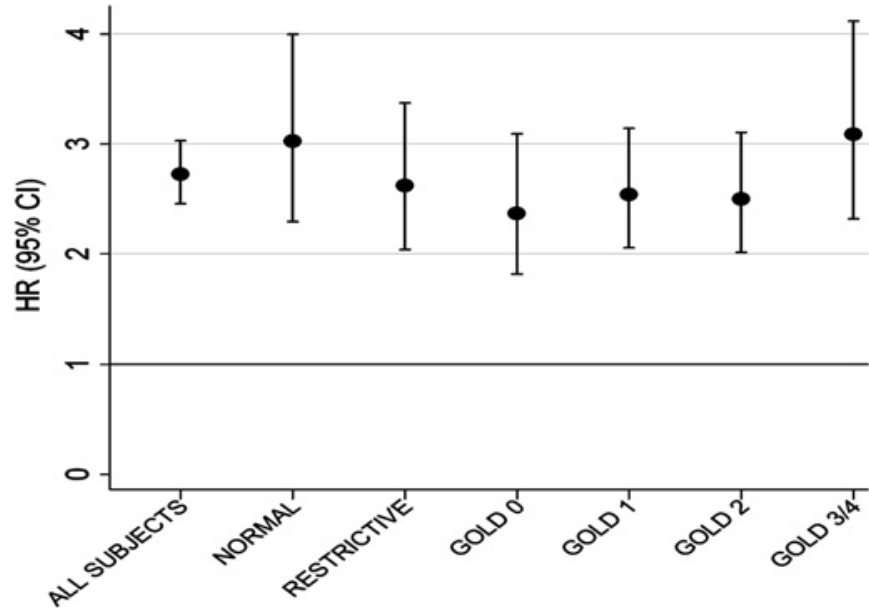

Figure 3 Risk of all-cause mortality over a median 10-year follow-up period associated with COPD hospitalisation (adjusted ${ }^{*} \mathrm{HR}$ and $95 \% \mathrm{CI}$ ), stratified by modified Global Initiative on Obstructive Lung Disease (GOLD) stage group. *Parametric survival regression model also adjusted for previous COPD admissions, age, gender, education, race, smoking, physical activity, body mass index, diabetes, heart disease and cohort (Atherosclerosis Risk in Communities Study/Cardiovascular Health Study). Modified GOLD stages: normal (no lung disease), restricted $\left(\mathrm{FEV}_{1} / \mathrm{FVC} \geq 0.70\right.$ and $\mathrm{FVC}<80 \%$ predicted), GOLD stage 0 (presence of respiratory symptoms in the absence of any lung function abnormality), GOLD stage 1 (FEV $1 / F V C<0.70$ and $\mathrm{FEV}_{1} \geq 80 \%$ ), GOLD stage $2\left(\mathrm{FEV}_{1} / \mathrm{FVC}<0.70\right.$ and $\mathrm{FEV}_{1} \geq 50 \%$ to $<80 \%$ predicted) and GOLD stages 3 or 4 (FEV $1 / F V C<0.70$ and $\mathrm{FEV}_{1}<50 \%$ predicted).

could be measured in adults with 'normal' lung function at baseline and comprised 9\% of the cohort with at least one COPD hospitalisation (table 1). If one combines this group with the GOLD stage 0 group and the restricted group, about $34 \%$ of the cohort in whom at least one incident COPD hospital admission occurred did not meet traditional spirometric definitions of COPD at baseline. There are several possible explanations for this finding. Some of these hospital admissions could represent misdiagnosis or miscoding of the underlying lung disease. Several studies have demonstrated poor documentation of lung function in hospitalised patients with a COPD diagnosis. ${ }^{31}$ Some of these hospital admissions could represent subtypes of COPD-for example, patients with normal flows but impaired diffusion and radiographic evidence of emphysema or those with evidence of air trapping but no airflow limitation. ${ }^{32}$ Other hospital admissions could represent incident cases: patients whose lung function rapidly declined over a very short period of time. While the traditional view of the natural history of COPD views accelerated loss of lung function as being 60-90 $\mathrm{ml}$ annually of $\mathrm{FEV}_{1}$, some patients have exhibited changes in their FEV $\mathrm{F}_{1}$ that far exceed this level. ${ }^{33} 34$

Our analysis reported a 50\% mortality rate within 5 years following a COPD hospitalisation (figure 2). These results are comparable to other studies which have observed a $23 \%$ mortality rate at 1 year, ${ }^{35}$ a $35.6 \%$ mortality rate at 2 years ${ }^{36}$ and a $51.1 \%$ mortality at 5 years ${ }^{15}$ in different populations. A novel finding in this analysis, however, is that the association between COPD-related hospitalisation and subsequent mortality was consistently increased, regardless of the level of baseline lung function. This finding highlights the importance of COPD-related hospitalisations as key sentinel events in the lives of patients with COPD which ultimately impacts the most important outcome of survival. 
In COPD and other chronic diseases characterised by exacerbations, such as congestive heart failure, each severe event that results in a hospitalisation has the potential to be lethal during the acute event. Our results expand this concept, however, by suggesting that an increased risk of death persists after each acute event, irrespective of the number of previous events. The possible explanations of this finding include debilitation that results during and after the hospitalisation, ${ }^{37}$ development of additional comorbid disease $e^{38}$ or that hospitalisation represents a surrogate marker for a poor functional status that increases mortality risk. ${ }^{39}$

This study has a number of limitations. Lung function was classified based on prebronchodilator measurements as bronchodilators were not administered in the ARIC and CHS studies. This may have resulted in the misclassification of some study subjects. In addition, we only used the baseline lung function and respiratory symptoms to classify subjects, raising the possibility that these predictors may have changed over time. Hospitalisation codes were not independently validated, with the possibility of further misclassification.

\section{CONCLUSION}

This analysis of a population-based cohort shows that impaired lung function-including mild COPD (GOLD stage 1), restriction on spirometry and respiratory symptoms in the presence of normal lung function-is associated with an increased risk of COPD-related hospitalisation during follow-up. Furthermore, the presence of a COPD-related hospitalisation was independently associated with risk of death regardless of the baseline level of lung function impairment. These findings highlight the critical importance of these severe exacerbation events in the lives of our patients. Additional epidemiological studies are warranted to understand better the factors that increase mortality so dramatically after a COPD hospitalisation. Clinically, patients who have experienced a COPD-related hospitalisation have an increased risk of death after discharge and their disease needs to be treated as aggressively as other sentinel events, such as an acute myocardial infarction, in order to improve outcomes.

Acknowledgements The authors thank the staff and participants in the Atherosclerosis Risk in Communities Study and the Cardiovascular Health Study for their important contributions.

Funding This study was funded by a research grant from GlaxoSmithKline. JG-A has a researcher contract from the Instituto de Salud Carlos III (CP05/00118), Ministry of Health, Spain. The Atherosclerosis Risk in Communities (ARIC) Study and Cardiovascular Health Study (CHS) are conducted and supported by the National Heart Lung and Blood Institute (NHLBI) in collaboration with the ARIC and CHS Investigators. This paper was not prepared in collaboration with investigators of the ARIC or the CHS and does not necessarily reflect the opinions or views of the ARIC investigators, CHS investigators or the NHLBI.

Competing interests DMM has served as a consultant to GlaxoSmithKline, Novartis, Pfizer, Forest, Astra-Zeneca and Boehringer-Ingelheim and has received research funding from GlaxoSmithKline, Novartis, Pfizer and Boehringer-Ingelheim. DPM was an employee of GlaxoSmithKline when this manuscript was developed. KJD is a current employee of GlaxoSmithKline. The other authors have no competing interests.

Provenance and peer review Not commissioned; externally peer reviewed.

\section{REFERENCES}

1. Murray CJ, Lopez AD. Alternative projections of mortality and disability by cause 1990-2020: Global Burden of Disease Study. Lancet 1997;349:1498-504.

2. Mannino DM, Homa DM, Akinbami LJ, et al. Chronic obstructive pulmonary disease surveillance-United States, 1971-2000. MMWR Surveill Summ 2002:51:1-16.

3. Mannino DM. Chronic obstructive pulmonary disease: definition and epidemiology. Respir Care 2003;48:1185-91.

4. Connolly MJ, Lowe D, Anstey K, et al. Admissions to hospital with exacerbations of chronic obstructive pulmonary disease: effect of age related factors and service organisation. Thorax 2006;61:843-8
5. McGhan R, Radcliff $T$, Fish $R$, et al. Predictors of rehospitalization and death after a severe exacerbation of COPD. Chest 2007;132:1748-55.

6. Fuso L, Incalzi RA, Pistelli R, et al. Predicting mortality of patients hospitalized for acutely exacerbated chronic obstructive pulmonary disease. Am J Med 1995; 98:272-7.

7. Miravitlles M, Guerrero T, Mayordomo C, et al; The EOLO Study Group. Factors associated with increased risk of exacerbation and hospital admission in a cohort of ambulatory COPD patients: a multiple logistic regression analysis. Respiration 2000;67:495-501.

8. Garcia-Aymerich J, Monso E, Marrades RM, et al. Risk factors for hospitalisation for a chronic obstructive pulmonary disease exacerbation. EFRAM study. Am J Respir Crit Care Med 2001:164:1002-7.

9. Roberts CM, Lowe D, Bucknall CE, et al. Clinical audit indicators of outcome following admission to hospital with acute exacerbation of chronic obstructive pulmonary disease. Thorax 2002;57:137-41.

10. Garcia-Aymerich J, Farrero E, Felez MA, et al. Risk factors of readmission to hospital for a COPD exacerbation: a prospective study. Thorax 2003:58:100-5.

11. Gudmundsson G, Gislason T, Janson C, et al. Risk factors for rehospitalisation in COPD: role of health status, anxiety and depression. Eur Respir J 2005;26:414-19.

12. Garcia-Aymerich $\mathbf{J}$, Lange $P$, Benet $\mathbf{M}$, et al. Regular physical activity reduces hospital admission and mortality in chronic obstructive pulmonary disease: a population based cohort study. Thorax 2006;61:772-8.

13. Patil SP, Krishnan JA, Lechtzin N, et al. In-hospital mortality following acute exacerbations of chronic obstructive pulmonary disease. Arch Intern Med 2003;163:1180-6.

14. FitzGerald JM, Haddon JM, Bradly-Kennedy C, et al. Resource use study in COPD (RUSIC): a prospective study to quantify the effects of COPD exacerbations on health care resource use among COPD patients. Can Respir J 2007:14:145-52.

15. Kinnunen T, Saynajakangas 0, Keistinen T. The COPD-induced hospitalization burden from first admission to death. Respir Med 2007;101:294-9.

16. Price LC, Lowe D, Hosker HS, et al. UK National COPD Audit 2003: impact of hospital resources and organisation of care on patient outcome following admission for acute COPD exacerbation. Thorax 2006:61:837-42.

17. Connors AF Jr, Dawson NV, Thomas C, et al. Outcomes following acute exacerbation of severe chronic obstructive lung disease. The SUPPORT investigators (Study to Understand Prognoses and Preferences for Outcomes and risks of Treatments). Am J Respir Crit Care Med 1996:154(4 Pt 1):959-67.

18. Gudmundsson G, Gislason T, Lindberg E, et al. Mortality in COPD patients discharged from hospital: the role of treatment and co-morbidity. Respir Res 2006; 7:109.

19. Seneff MG, Wagner DP, Wagner RP, et al. Hospital and 1-year survival of patients admitted to intensive care units with acute exacerbation of chronic obstructive pulmonary disease. JAMA 1995;274:1852-7.

20. McGhan R, Radcliff T, Fish R, et al. Predictors of rehospitalization and death after a severe exacerbation of COPD. Chest 2007;132:1748-55.

21. Fried LP, Borhani NO, Enright $P$, et al. The Cardiovascular Health Study: design and rationale. Ann Epidemiol 1991;1:263-76.

22. ARIC Investigators. The Atherosclerosis Risk in Communities (ARIC) Study: design and objectives. Am J Epidemiol 1989;129:687-702.

23. American Thoracic Society. Standardization of spirometry. Am Rev Respir Dis 1979;119:831-8

24. Hankinson JL, Odencrantz JR, Fedan KB. Spirometric reference values from a sample of the general U.S. population. Am J Respir Crit Care Med 1999;159:179-87.

25. Pauwels RA, Buist AS, Calverley PM, et al. Global strategy for the diagnosis, management, and prevention of chronic obstructive pulmonary disease. NHLBI/WHO Global Initiative for Chronic Obstructive Lung Disease (GOLD) workshop summary. Am J Respir Crit Care Med 2001;163:1256-76.

26. Celli BR, Macnee W. Standards for the diagnosis and treatment of patients with COPD: a summary of the ATS/ERS position paper. Eur Respir J 2004;23:932-46.

27. Baecke JA, Burema J Frijters JE. A short questionnaire for the measurement of habitual physical activity in epidemiological studies. Am J Clin Nutr 1982:36:936-42

28. Pereira MA, Folsom AR, McGovern PG, et al. Physical activity and incident hypertension in black and white adults: the Atherosclerosis Risk in Communities Study. Prev Med 1999:28:304-12

29. Anon. Executive summary of the clinical guidelines on the identification, evaluation, and treatment of overweight and obesity in adults. Arch Intern Med 1998:158:1855-67.

30. Tashkin DP, Celli B, Senn S, et al. A 4-year trial of tiotropium in chronic obstructive pulmonary disease. N Engl J Med 2008;359:1543-54.

31. Joo MJ, Lee TA, Weiss KB. Geographic variation of spirometry use in newly diagnosed COPD. Chest 2008;134:38-45.

32. Hyatt RE, Cowl CT, Bjoraker JA, et al. Conditions associated with an abnormal nonspecific pattern of pulmonary function tests. Chest 2009;135:419-24.

33. Fletcher C, Peto R, Tinker CM, et al. The Natural History of Chronic Bronchitis and Emphysema. Oxford University Press, 1976.

34. Habib MP, Klink ME, Knudson DE, et al. Physiologic characteristics of subjects exhibiting accelerated deterioration of ventilatory function. Am Rev Respir Dis 1987:136:638-45.

35. Groenewegen $\mathbf{K H}$, Schols AM, Wouters EF. Mortality and mortality-related factors after hospitalization for acute exacerbation of COPD. Chest 2003;124:459-67. 
36. Almagro P, Calbo E, de Echaguen A0, et al. Mortality after hospitalization for COPD. Chest 2002;121:1441-8.

37. Formiga F, Lopez-Soto A, Masanes F, et al. Influence of acute exacerbation of chronic obstructive pulmonary disease or congestive heart failure on functional decline after hospitalization in nonagenarian patients. Eur J Intern Med 2005:16:24-8.
38. Barr RG, Celli BR, Mannino DM, et al. Comorbidities, patient knowledge, and disease management in a national sample of patients with COPD. Am J Med 2009; 122:348-55.

39. Fan VS, Ramsey SD, Make BJ, et al. Physiologic variables and functional status independently predict COPD hospitalisations and emergency department visits in patients with severe COPD. COPD 2007;4:29-39.

\section{Journal club}

\section{Innovative new diagnostic test to detect TB and rifampin resistance}

Tuberculosis remains a major public health concern. Existing diagnostic tools are slow and result in delays initiating appropriate treatment. This is particularly a problem in patients with HIV, in whom sputum-smear analysis is frequently negative and those with multi-drug resistant strains.

In this study, the performance of an automated molecular assay for Mycobacterium tuberculosis (MTB) and resistance to rifampin (RIF) (Xpert MTB/RIF) was assessed. This test, through detection of an MTB-specific sequence of the rpoB gene and probing for rifampinresistance determining region mutations, provides results within $2 \mathrm{~h}$.

Three sputum samples were analysed from 1730 eligible patients with suspected tuberculosis in reference laboratories in Peru, Azerbaijan, South Africa and India. With a single test, $98.2 \%$ of patients with smear-positive, culture-positive tuberculosis were identified. Among those with smear-negative, culture-positive disease, the sensitivity of the assay was $72.5 \%$ with one test, $85.1 \%$ for two tests and $90.2 \%$ for three tests. The diagnostic specificity for tuberculosis was $99.2 \%$. MTB/RIF testing correctly identified $97.6 \%$ of bacteria which had exhibited rifampin-resistance on phenotypic drug-susceptibility screening.

The MTB/RIF assay provides a prompt sensitive method of detection of tuberculosis and its potential resistance to rifampin. The benefit of a point-of-contact diagnostic test, with low man-power implications, sounds attractive for poorly funded healthcare systems. However, the authors admit several limitations to its uptake including high initial costs, rifampinresistance testing only and a need to demonstrate similar efficacy in other healthcare settings.

Boehme CC, Nabeta P, Hillemann D, et al. Rapid molecular detection of tuberculosis and rifampin resistance. N Engl J Med 2010;363:1005-15.

\section{Narendra Babu Chinnappa}

Correspondence to Dr Narendra Babu Chinnappa, SpR, University Hospital Llandough, 74 Pan-Ty-Celyn road, Llandough, Cardiff CF64 2PH, UK; rcnaren@yahoo.com

Published Online First 3 November 2011

Thorax 2011:66:590. doi:10.1136/thx.2010.153528 